\title{
Relativizando o Leviatã: Empresários e Política Econômica no Governo Jânio Quadros ${ }^{\star}$
}

\author{
- Felipe Pereira Loureiro*
}

\begin{abstract}
Resumo
Este artigo examina as atitudes dos empresários brasileiros relacionadas à política econômica do governo Jânio Quadros. A análise se concentra nas associações de classe paulistas dos empresários industriais, comerciais e agrícolas. Argumenta-se que esses grupos apresentaram um importante papel na formulação dessa política econômica, particularmente sobre a política cambial, creditícia e da legislação antitruste. As evidências coletadas neste artigo trazem novas luzes sobre a elaboração da política econômica durante esse período crítico da história brasileira.
\end{abstract}

\section{Palavras-Chave}

política econômica, Jânio Quadros, empresários, grupos de interesse, Instrução nº 204

\begin{abstract}
This article examines the Brazilian entrepreneurs ' attitudes towards the economic policy of Jânio Quadros ' government. The analysis concentrates on the São Paulo's associations of industrial, commercial and agricultural employers. It is argued that these groups played an important role in shaping economic policies, in particular those related to the exchange rate, credit and antitrust legislation. The evidences gathered in this article bring new light on the management of economic policy during a critical period of Brazilian history.
\end{abstract}

\section{Keywords}

economic policy, Jânio Quadros, entrepreneurs, interest groups, Instruction n 204

\section{JEL Classification}

N16, N26, N46

- Agradeço a Claudia Simionato, Gustavo Barros, Hildete Pereira, Renato Colistete, Tereza Spyer e Thomas Kang e aos pareceristas da Estudos Econômicos pelos profícuos comentários e sugestões. Naturalmente, erros e omissões remanescentes são de minha inteira responsabilidade. Este artigo é uma versão modificada do trabalho apresentado pelo autor no $36^{\circ}$ Encontro Nacional de Economia da Associação Nacional de Centros de Pós-Graduação em Economia (ANPEC).

* Faculdade de Filosofia, Letras e Ciências Humanas, Universidade de São Paulo (FFLCH-USP). E-mail: fpeloureiro@gmail.com.

Endereço para contato: Av. Washington Luis, 193, ap. 39 - Santos - SP. CEP: 11050-201.

(Recebido em janeiro de 2009. Revisões requeridas em setembro de 2009 . Aceito para publicação em outubro de 2009). 
Uma das características mais marcantes da maioria dos trabalhos sobre a política econômica do governo Jânio Quadros é a negligência quanto ao papel do empresariado no processo de aplicação dessa política. Os agentes estatais são vistos, nessa perspectiva, como os únicos responsáveis pelas modificações nos rumos da política econômica, em que a presença dos grupos e atores sociais teve pouca ou nenhuma importância. ${ }^{1}$

Neste artigo, pretende-se analisar de que maneira o empresariado interpretou e reagiu aos aspectos centrais da política econômica do governo Jânio Quadros, em particular a política cambial, a política monetária e a tentativa de aprovação no Congresso Nacional da Lei Antitruste, que regulamentaria os abusos de poder econômico. Apesar da brevidade da administração janista, é consenso entre os estudiosos o fato de que as suas medidas econômicas representaram uma mudança considerável nas diretrizes da política econômica até então vigente. Sabe-se, porém, que tais mudanças não duraram muito, principalmente no que se refere às políticas monetária e fiscal. Já ao final do governo Quadros, era possível perceber que elas não estavam mais sendo postas em prática com a mesma intensidade. É de se perguntar, portanto, quais teriam sido os motivos que impediram a continuidade das políticas do governo Quadros. A tendência na historiografia tem sido a de buscar razões no âmbito do Estado como responsáveis pelas mudanças na política econômica. A discussão a seguir avalia a consistência dessa hipótese, com base no estudo das visões e da atuação das classes empresariais. ${ }^{2}$

O artigo utiliza fontes primárias, tais como relatórios de diretoria, boletins informativos e atas de reunião de diretores, oriundas das principais entidades empresariais paulistas da indústria, do comércio e da agricultura do início da década de 1960, especialmente da Federação das Indústrias do Estado de São Paulo (FIESP), da Associação Comercial do Estado de São Paulo (ACSP) e da Sociedade Rural Brasileira (SRB). ${ }^{3}$ Essas associações foram privilegiadas devido a sua representatividade entre a classe empresarial e ao considerável acesso que elas possuíam às autoridades do governo responsáveis pela formulação da política econômica. ${ }^{4}$

Além disso, a partir da consulta de dois periódicos de abrangência nacional $(O$ Estado de São Paulo e Última Hora), foram analisados notas e manifestos produzi-

1 Ver Bandeira (1970), Mesquita (1992), Monteiro (1999) e Skidmore (2000). Já Leopoldi (2000) deu ênfase ao papel das entidades empresariais na formulação da política econômica entre 194661, mas tratou marginalmente do período do governo Quadros.

2 Mesquita (1992, p. 50-60) e Monteiro (1999, p. 70).

3 A documentação da FIESP pode ser encontrada na Biblioteca Roberto Simonsen, localizada no Instituto de Filosofia e Ciências Humanas da Universidade de Campinas (IFCH-Unicamp). Já, por sua vez, as fontes referentes à ACSP e à SRB foram consultadas nas próprias sedes dessas entidades, que se situam no município de São Paulo.

4 Sobre a proeminência obtida pelas entidades empresariais paulistas nos órgãos estatais, especialmente durante a década de 1950, ver Leopoldi (2000, p. 88-90). 
dos por outras importantes entidades empresariais, a saber: Confederação Nacional da Agricultura (CNA), Confederação Nacional do Comércio (CNC), Confederação Nacional da Indústria (CNI), Federação das Indústrias do Estado da Guanabara (FIEGA), Federação das Associações Comerciais (FAC) e Associação Comercial do Rio de Janeiro (ACRJ). A pesquisa em jornais também foi de extrema valia para que fossem obtidas informações gerais acerca do cotidiano da política econômica do governo Quadros, bem como analisados os principais pronunciamentos de autoridades políticas.

Além desta introdução, o artigo está dividido em quatro seções: na primeira, realizase um breve balanço das linhas gerais da política econômica e das interpretações sobre o governo Jânio Quadros; nas segunda e terceira seções, analisa-se a atuação do empresariado em relação às políticas cambial e monetária e quanto à tentativa de aprovação da Lei Antitruste. Na última seção, são apresentadas as conclusões das principais evidências examinadas no artigo.

\section{Linhas Gerais e Interpretações da Política Econômica}

Em sua fase inicial, como se pode depreender dos pronunciamentos do Presidente da República e de outras autoridades governamentais, o principal objetivo da política janista era o de sanear os desequilíbrios econômicos externos e internos herdados da administração Juscelino Kubitschek. ${ }^{5}$ Apenas em atrasados comerciais, em coberturas de Promessas de Venda de Câmbio (PVC) e em serviços da dívida estrangeira, o País teria de desembolsar, em 1961, aproximadamente U\$S 1,5 bilhão. Essa quantia se encontrava muito acima da capacidade de pagamento doméstica. Além disso, o déficit potencial de caixa do Tesouro Nacional, para 1961, seria superior a Cr\$ 237 bilhões. Além desses problemas, assistia-se a um aumento contínuo dos índices de preços, o que inviabilizava qualquer tentativa de cobertura dos desequilíbrios das contas públicas via emissões monetárias. ${ }^{6}$

A fim de resolver o problema do desequilíbrio externo, o governo Quadros atuou em duas frentes: realizou uma reforma no sistema de câmbio e iniciou tentativas de renegociação da dívida externa. A publicação da Instrução no 204 da SUMOC

5 Conforme o discurso feito por Jânio Quadros na Hora do Brasil, no dia de sua posse como Presidente da República (31.01.1961), e o discurso do Ministro da Fazenda, Clemente Mariani, no Parlamento, realizado em abril de 1961. Ver O Estado de São Paulo (OESP, 01.02.1961, p. 10; e 20.04.1961, p. 5-7).

6 As informações citadas nessa seção referentes à política econômica janista foram extraídas de Abreu (1990, p. 198-200), Baer (2002, p. 91-95), Mesquita (1992, p. 56-117), Monteiro (1999, p. 58-70) e Victor (1965, p. 110-137). 
simbolizou o início da reforma cambial janista. ${ }^{7}$ Em linhas gerais, essa instrução buscava unificar as diferentes taxas de câmbio existentes. As divisas para a importação de produtos pertencentes à categoria "geral" seriam obtidas no mercado livre. As cambiais, da categoria "especial" - referentes aos bens de luxo e/ou considerados supérfluos pelas autoridades econômicas -, ainda seriam adquiridas em leilões, porém ofertadas em quantidades restritas. Além disso, permitiu-se que os exportadores vendessem suas divisas livremente no mercado, com a exceção daqueles que exportavam café ou cacau. O câmbio de custo, que englobava os produtos cuja importação era subsidiada pelo governo - tais como trigo, petróleo e papel de imprensa -, foi desvalorizado em $100 \%$. Por fim, estipularam-se limitações para a compra de cambiais da categoria "geral": haveria cotas de divisas semanais por pessoa jurídica (U\$S 20.000), bem como a obrigatoriedade de o importador obter letras do Banco do Brasil no mesmo valor das divisas por ele compradas. Tais letras seriam readquiridas pelo governo em cinco meses, com juros de $6 \%$ mensais.

De um modo geral, pode-se dizer que as instruções baixadas subsequentemente pela SUMOC, entre maio e julho de 1961, aprofundaram ainda mais esse processo de unificação cambial, sinalizando também para postura mais liberal do governo com relação à oferta de crédito e às importações. A Instrução $n^{\circ} 205$, por exemplo, transferiu a venda de divisas decorrentes das exportações do café para o mercado livre. Os cafeicultores, no entanto, deveriam pagar uma "cota de contribuição" de U\$S 22,00 por saca do produto, a fim de financiar o programa de defesa do café. A Instrução no 206 modificou o valor da "cota de contribuição" cafeeira (de U\$S 22,00 para Cr\$ 80,00), aumentou o limite de compra de divisas semanais da categoria "geral" pelas pessoas jurídicas (de U\$S 20.000 para U\$S 50.000) e estabeleceu condições para liberações adicionais de redescontos pelo Banco do Brasil aos bancos privados. A Instrução $\mathrm{n}^{\circ} 207$ diminuiu as taxas de encaixe compulsório dos bancos comerciais em relação ao Banco do Brasil, tanto para depósitos à vista (12\%), como para os depósitos a prazo (6\%). A Instrução no 208, por fim, suprimiu o "câmbio de custo", transferiu para o mercado livre as divisas referentes às transações financeiras, reduziu ainda mais a taxa do compulsório dos bancos comerciais (10\% para depósitos à vista e $5 \%$ para depósitos a prazo) e liberou a importação de máquinas e equipamentos da necessidade de adquirir letras do Banco do Brasil.

A disposição do governo Jânio em suprimir o sistema de taxas múltiplas de câmbio foi essencial ao processo de renegociação da dívida externa brasileira com os credores internacionais, especialmente os norte-americanos. A confiança desses credores aumentou ainda mais com o programa de ajuste das finanças públicas iniciado pela administração janista. Esse programa incluía o corte de gastos governamentais, au-

7 Para informações sobre as mudanças realizadas no regime cambial brasileiro no período 1946 a 1961, ver Baer (2002, p. 72-78). 
mento na receita tributária e a fixação de metas nominais rígidas para a expansão do crédito aos setores privado e público. Pretendia-se fechar o ano de 1961 com um déficit de caixa de apenas Cr\$50 bilhões; valor este modesto quando comparado aos Cr\$ 237 bilhões estimados como potencial para aquele exercício. Admitia-se que, nos primeiros meses do governo, os déficits seriam inevitáveis, devido, em especial, aos ajustes cambiais realizados. Mesmo assim, o governo conseguiu cumprir suas metas. Tanto que foi nesse contexto, entre os meses de abril e maio, que o País obteve êxito na renegociação de grande parte da sua dívida externa. ${ }^{8}$

Em junho de 1961, porém, o déficit de caixa do Tesouro atingiu o montante de Cr\$ 47,9 bilhões (isto é, próximo à meta estipulada para o ano inteiro). As autoridades argumentaram que, mesmo assim, o plano financeiro teria totais condições de ser cumprido, na medida em que os acréscimos de arrecadação tributária, previstos para os últimos dois trimestres de 1961, iriam compensar os déficits já esperados para os meses anteriores. ${ }^{9}$ De fato, a arrecadação cresceu consideravelmente no trimestre seguinte; as despesas, no entanto, diferentemente do que fora planejado, expandiram-se nas mesmas proporções, enfraquecendo o programa de ajuste das finanças públicas. Em agosto de 1961, por exemplo, o déficit de caixa já se encontrava em $\mathrm{Cr} \$ 57,2$ bilhões (Cr\$ 7 bilhões a mais do que o previsto). A evolução da oferta de crédito do Banco do Brasil ao setor privado apresentou tendência semelhante à do controle do déficit do Tesouro. Entre fevereiro e abril de 1961, houve forte contração creditícia, cumprindo-se o planejamento inicial; a partir de maio, no entanto, quando foram publicadas as Instruções n ${ }^{\circ}$ 206, 207 e 208, a oferta real de empréstimos cresceu continuamente, com destaques para os meses de junho $(3,76 \%)$ e julho $(2,22 \%)$, como é possível observar na Tabela 1.

8 O País obteve U\$S 656 milhões em créditos novos e U\$S 859 milhões para reescalonamento da dívida externa anterior. Monteiro (1999, p. 62).

9 Ver, por exemplo, nota do Ministro da Fazenda, Clemente Mariani, divulgada em junho de 1961. OESP (07.06.1961, p. 6). 
Tabela 1 - Execução Financeira da União e Empréstimos das Autoridades Monetárias ao Setor Privado (Janeiro a Agosto de 1961, em Bilhões de Cr\$)

\begin{tabular}{|c|c|c|c|c|c|c|}
\hline \multirow[t]{2}{*}{ Meses } & \multicolumn{3}{|c|}{ Execução Financeira da União } & \multicolumn{3}{|c|}{ Empréstimos ao Setor Privado } \\
\hline & Receita & Despesa & Déficit & Total & (1) & (2) \\
\hline Janeiro & 11,8 & 21,2 & $-9,4$ & 176,8 & $-3,17$ & $-5,22$ \\
\hline Fevereiro & 28,6 & 46,1 & $-17,5$ & 173,9 & $-1,68$ & $-1,35$ \\
\hline Março & 47,3 & 68,9 & $-21,6$ & 175,6 & 0,99 & $-1,34$ \\
\hline Abril & 64,8 & 95,4 & $-30,6$ & 176,8 & 0,69 & $-4,52$ \\
\hline Maio & 87,9 & 124,2 & $-36,3$ & 182,1 & 3,01 & 1,54 \\
\hline Junho & 117,2 & 159,3 & $-42,1$ & 193,4 & 6,2 & 3,76 \\
\hline Julho & 150,0 & 197,9 & $-47,9$ & 199,5 & 3,14 & 2,22 \\
\hline Agosto & 182,2 & 239,4 & $-57,2$ & 212,1 & 6,32 & 0,35 \\
\hline
\end{tabular}

Fonte: Conjuntura Econômica, fevereiro de 1962, apud Monteiro (1999, p. 67 e 69)

Notas: (1) \% Variação nominal; (2) \% Variação real (valores deflacionados pelo IPA-DI)

Duas foram as explicações dadas pela historiografia para essa alteração dos rumos da política econômica janista. De um lado, Lourdes Sola argumentou que tal mudança se deveu ao reconhecimento de um "erro de cálculo" por parte dos técnicos e dos formuladores políticos. A raiz desse "erro" se encontraria, segundo a autora, não nas ideias desses profissionais, mas, sim, na "ausência de instituições adequadas" para a aplicação de uma política ortodoxa tal como prevista pelo governo Quadros, vide, por exemplo, a falta de um Banco Central (SOLA, 1998, p. 253). Posicionamento semelhante, porém menos enfático quanto às alterações do rumo da política econômica, é o de Mário Mesquita (1992). Segundo o autor, o governo se viu prejudicado pelo escopo limitado dos instrumentos de política econômica existentes, bem como pela falta de consciência dos técnicos acerca das consequências inflacionárias da reforma cambial. Isso explicaria, de acordo com Mesquita, o porquê de o governo ter aumentado as operações de redesconto a partir de maio de 1961 (MESQUITA, 1992, p. 107-108 e 111).

Do outro lado, tem-se o argumento de Sérgio Monteiro (1999), baseado no conceito de populismo e na Teoria da Escolha Racional. Conforme o autor, o político populista, a fim de obter legitimidade perante as massas, tinha de privilegiar o crescimento econômico, visto como a única maneira de garantir rendas absolutas crescentes para as classes trabalhadoras sem que a concentração da renda na sociedade fosse alterada. Com isso, tal político continuaria recebendo o apoio da burguesia nacional e, ao mesmo tempo, angariando os votos dos trabalhadores. Na medida em que Monteiro assume os atores políticos como racionais e como desejosos de manterem-se sempre no poder, o político populista tenderia a buscar, segundo o autor, a formulação de 
uma política econômica que visasse o crescimento imediato. Quando isso não fosse possível, como era o caso do Brasil no início dos anos 1960, esse político partiria para uma tática de dissimulação a fim de obter, por exemplo, a rolagem da dívida externa do País. Primeiramente, ele implementaria políticas fiscais e monetárias ortodoxas, ao lado da liberalização cambial. Uma vez obtida a "credibilidade" perante os agentes econômicos externos, o político populista iniciaria a segunda fase da sua política econômica, ou seja, o abandono da estabilização e a concentração no objetivo de crescimento imediato da economia. O governo Jânio, de acordo com o autor, teria se enquadrado perfeitamente nesse modelo (MONTEIRO, 1999, p. 122-128).

Apesar das diferenças entre as duas interpretações, elas apresentam um importante aspecto comum: ambas veem os agentes ou as instituições estatais como responsáveis quase que únicos pela alteração dos rumos da política econômica janista, seja devido à falta de consciência por parte dos técnicos quanto às implicações dos mecanismos empregados, à ineficácia dos instrumentos de política econômica disponíveis, ou até em razão de um plano deliberado dos governantes de mudar os rumos da política econômica inicial. No tópico seguinte, será argumentado que a posição expressa pela historiografia sobre o tema apresenta limitações, uma vez que há evidências de que a atuação das classes empresariais foi também um fator determinante para a alteração das diretrizes da política econômica do governo Quadros.

\section{Câmbio e Crédito}

Eram amplamente conhecidas as propostas de Jânio Quadros para a economia brasileira. Em vários dos seus discursos ao longo da campanha, o candidato reiterou a necessidade de realização de uma reforma cambial e de uma política de combate à inflação. Esta política envolveria, entre outras medidas, corte de gastos públicos e restrições à expansão monetária.

Apesar disso, os círculos empresariais não sabiam nem quando e, muito menos, com que intensidade tais mudanças se dariam, assim que Jânio Quadros tomasse posse. No momento, porém, em que foi publicada a Instrução no 204 da SUMOC, em 13 de março de 1961, as discussões sobre as consequências dessa medida para a economia brasileira logo se instalaram no interior das entidades empresariais. No geral, o empresariado prestou apoio à instrução baixada pelo governo.

Camilo Ansarah, Presidente da ACSP, por exemplo, distribuiu nota afirmando que a reforma cambial feita pela administração Quadros receberia todo suporte do comércio paulista, na medida em que ela teria se pautado pela eliminação dos "diversos 
artificialismos do sistema" e pelo abandono das "práticas econômicas imediatistas", enveredando "corajosamente para uma reforma de grande amplitude". ${ }^{10}$

A lavoura, por sua vez, também se mostrou favorável à Instrução $n^{0} 204$, principalmente devido aos ganhos que adviriam para o setor agrário-exportador como decorrência do processo de liberalização do câmbio. Em reunião na SRB, o Diretor do Departamento do Café da entidade, Plínio Cavalcanti de Albuquerque, avaliou os efeitos da instrução em nome da diretoria. Segundo ele, a agricultura em geral beneficiou-se muito com a reforma, pois esta "marcou praticamente o fim das importações subsidiadas", as quais teriam sido responsáveis pela "mentira cambial" que tanto desfavorecera a lavoura até aquele momento. ${ }^{11}$

Os industriais da FIESP, da mesma maneira, salientaram que a Instrução no 204 suscitaria efeitos positivos para a economia, especialmente devido ao auxílio em prol do saneamento das contas públicas. Segundo o diretor do Departamento de Economia Industrial da Federação, Sérgio Roberto Ugolini, a desvalorização do câmbio de custo, promovida pela reforma cambial, permitiria ao Estado cortar gastos, na medida em que seriam reduzidos os recursos governamentais necessários à manutenção dos subsídios para a importação de certos produtos, tais como o trigo e o petróleo. ${ }^{12}$

É de se salientar, no entanto, que o suporte prestado pelas classes empresariais à Instrução $n^{\circ} 204$ não foi, de maneira alguma, absoluto. Por exemplo, um dos principais diretores da SRB, Plínio Cavalcanti, afirmou que seria preciso controlar a alta de preços que certamente adviria da reforma cambial, em razão do encarecimento das importações. Segundo Cavalcanti, caso tal elevação de preços não fosse contida, as demandas trabalhistas por aumento salarial ganhariam ímpeto na sociedade, acarretando instabilidades para a democracia brasileira:

A elevação sensível do custo de vida conduzirá inevitavelmente às reivindicações de reajustamento salarial e, chegados nesse ponto, cairemos novamente no ciclo infernal de salários e preços. Nessa hora, o governo será alijado de todas simpatias populares e apontado como o responsável pelo agravamento da conjuntura inflacionária no País. ${ }^{13}$

10 OESP (16.03.1961, p. 26). Para posicionamento semelhante da ACSP, ver Ata da $46^{\circ}$ Reunião da Diretoria Plena da Associação Comercial de São Paulo (RDP da ACSP, 14.03.61, p. 15-29).

11 OESP (21.03.1961, p. 26).

12 OESP (17.03.1961, p. 25).

13 OESP (21.03.1961, p. 26). Para posicionamento semelhante da SRB, ver A Rural (AR, no 474, 05.1961, p. 03). 
Os industriais, da mesma forma, apresentaram ressalvas à Instrução no 204. Apesar de terem destacado a importância da simplificação do regime cambial para a economia brasileira, os diretores da FIESP assinalaram, em primeiro lugar, que a previsão feita pelo governo quanto ao impacto inflacionário da Instrução no 204 estaria subestimada, e que o tempo de adaptação da economia para o novo sistema relativo de preços poderia ser mais longo do que o previsto pelas autoridades. Em segundo, afirmou-se ainda que a obrigatoriedade de se comprar Letras do Banco do Brasil para a importação de bens da antiga categoria geral, estabelecida pela instrução, diminuiria a liquidez na economia, reduzindo a capacidade do mercado em ofertar crédito às empresas. Segundo o Diretor do Departamento de Economia Industrial da FIESP, Sérgio Ugolini, considerando-se que a indústria paulista importava, em média, U\$S 5 milhões de dólares em produtos por semana - isto é, U\$S 110 milhões em cinco meses (tempo mínimo para a restituição das Letras) -, seria preciso empregar nesse período, em títulos do Banco do Brasil, mais de Cr\$ 30 bilhões, quantia essa que haveria de ser retirada do mercado creditício. Conforme Ugolini, essa contração do crédito geraria implicações negativas para o setor industrial:

Evidentemente, o espírito da Instrução é dificultar o crédito e diminuir as facilidades de importação (...). Os reflexos dessa situação na indústria são evidentemente fortes, porque toda vez que houve uma intensa pressão de crédito no mercado normal bancário haverá também o encarecimento desse crédito. ${ }^{14}$

Além disso, o Departamento de Economia Industrial da FIESP assinalou, no mesmo relatório, que a obrigatoriedade de compra das Letras do Banco do Brasil representaria um reforço à desigualdade de condições existentes entre os capitais nacional e estrangeiro no Brasil; condições estas, segundo o relatório, que já estariam díspares desde a publicação da Instrução no 113 da SUMOC, em 1955. Seria necessário, portanto, de acordo com a FIESP, regulamentar a entrada de capitais externos no País, a fim de coibir tal disparidade. ${ }^{15}$

Portanto, vê-se que o apoio prestado pelas classes empresariais à Instrução no 204 não foi pleno. Se, de um lado, o empresariado aplaudiu o processo de simplificação e de liberalização do câmbio; do outro, porém, as entidades patronais demonstraram fortes indícios de que enxergavam limitações na reforma cambial, em especial quanto à questão do crédito, abordada enfaticamente pelos industriais.

$14 \operatorname{OESP}$ (17.03.1961, p. 25).

15 Idem. 
Com o tempo, porém, as críticas do empresariado à Instrução no 204 começaram a superar os elogios. ${ }^{16}$ Ainda no final de março de 1961, as diretorias da FIESP e da ACSP apresentaram uma declaração pública afirmando que a majoração de alguns preços se fazia "inevitável", seja devido à contração dos créditos, seja devido ao encarecimento de inúmeros bens importados. ${ }^{17}$ As reclamações dos empresários quanto à escassez de crédito ficaram ainda mais contundentes nos meses seguintes. ${ }^{18}$ No dia 23 de maio de 1961, por exemplo, a FIESP e a ACSP promoveram, na sede desta associação, um debate sobre a conjuntura econômica nacional, com a presença do Presidente do Banco do Brasil e ex-conselheiro da ACSP, João Batista Leopoldo Figueiredo. Naquela oportunidade, entregou-se a Figueiredo um estudo feito pelos técnicos da FIESP relativo ao problema do crédito no Brasil. Diferentemente do tom mais ameno quando da publicação da Instrução $n^{\circ} 204$, esse parecer assinalava que a escassez de crédito bancário para as atividades industriais e comerciais no Brasil estava atingindo "proporções alarmantes", ameaçando a afetar o ritmo da produção:

(...) com a contínua elevação dos custos de produção, esta política tenderá a colocar em risco não só a possibilidade do aumento da produção das empresas, mas o seu nível atual. E como o Governo Federal não deseja que o ritmo de desenvolvimento do País seja comprometido, é necessário que as autoridades monetárias tomem algumas medidas que contrabalancem os efeitos depressivos da sua presente política financeira no setor privado. ${ }^{19}$

Mais adiante, o estudo enumerou as principais medidas que deveriam ser tomadas pelo governo: expansão do redesconto para bancos particulares; ampliação das margens de empréstimos do Banco do Brasil às empresas privadas, de acordo com as novas condições de custos; redução dos depósitos compulsórios dos bancos particulares no Banco do Brasil, e eliminação, ou redução, do depósito prévio em Letras exigido quando da realização de importações.

Como resposta à demanda dos industriais e dos comerciantes paulistas, o Presidente do Banco do Brasil anunciou, naquele mesmo momento, que providências seriam tomadas com o intuito de conter a escassez dos meios de pagamento, as quais fo-

16 As entidades agrícolas, tais como a SRB, compuseram uma exceção nesse sentido. Ver, por exemplo, telegrama do Presidente da SRB, Renato Costa Lima, que continuou a elogiar a política cambial do governo, em OESP (25.05.1961, p. 24) e em $A R$ (no 484, 08.1961, p. 3).

17 OESP (30.03.1961, p. 2).

18 Ver, por exemplo, os telegramas enviados por representantes do comércio e da indústria às autoridades econômicas e ao Presidente Jânio Quadros em abril de 1961, em OESP (05.04.1961, p. 20).

19 OESP (03.06.1961, p. 16). Para maiores informações sobre o encontro promovido pela FIESP e pela ACSP com o Presidente do Banco do Brasil, ver Ata da 56 $6^{\circ}$ DP da ACSP (23.05.61). 
ram concretizadas na Instrução n 206 da SUMOC: elevação do limite semanal de importações para as pessoas jurídicas de U\$S 20.000 para U\$S 50.000, e maior "disposição" da Carteira de Redescontos do Banco do Brasil no que se refere à concessão de redescontos adicionais aos bancos privados. ${ }^{20}$

Essas medidas não satisfizeram os empresários industriais e do comércio. No início de junho de 1961, a FIESP enviou um telegrama ao Presidente da República, informando-o sobre a manutenção das precárias condições financeiras nas indústrias de São Paulo. A Federação assinalou que a única saída encontrada pelas empresas para se manterem capitalizadas foi a de aumentar os preços dos seus bens. Reivindicavase do Presidente, nesse sentido, medidas mais efetivas quanto à expansão dos meios de pagamento. ${ }^{21}$

Coincidência ou não, o fato é que, mais uma vez, dias depois de uma forte pressão dos industriais paulistas sobre as autoridades monetárias e o Presidente da República, promulgou-se nova medida voltada para melhorar as condições de crédito: a Instrução n 207 da SUMOC, que diminuiu o porcentual dos depósitos compulsórios dos bancos particulares no Banco do Brasil. É possível que apenas a pressão das entidades empresariais não tenha sido suficiente para determinar a mudança na política de crédito, mas é razoável sugerir que tal pressão deve ter exercido alguma influência sobre o governo. Além da ação do empresariado, é provável que os indicadores macroeconômicos tivessem reforçado a opinião entre os formuladores da política econômica acerca das dificuldades de manutenção das políticas monetária e cambial iniciais, tais como o aumento dos índices de preços e a queda do nível da atividade industrial apresentados em abril de 1961 (Tabela 2). A ameaça dos empresários da indústria em repassar suas dificuldades de capitalização para os preços dos produtos - o que, em certa medida, ocorreu nos dois primeiros meses pós-reforma cambial - também pode ter contribuído para essa avaliação.

$20 \operatorname{OESP}$ (24.05.1961, p. 21). As demandas por uma maior flexibilidade creditícia já estavam sendo feitas pela FIESP desde abril de 1961. Ver OESP (07.04.1961, p. 19). Para reivindicações semelhantes do comércio paulista, ver OESP (05.04.1961, p. 20).

21 OESP (09.06.1961, p. 21). Para reclamações semelhantes dos empresários comerciais, ver Ata da $58^{\circ}$ RDP da ACSP (06.06.61, p. 4-23). 
Tabela 2 - Índice de Atividade Industrial (IAI-FGV) e Índice de Preços ao Atacado (IPA-FGV), Janeiro a Agosto de 1961 (1953=100)

\begin{tabular}{lcc|cc}
\hline Meses & IAl-FGV & Variação \% & IPA-DI (\%) & IAP-DI (\%) \\
\hline Janeiro & 223 & $-0,45$ & 2,16 & 0,43 \\
Fevereiro & 224 & 0,45 & $-0,33$ & 0,10 \\
Março & 232 & 3,57 & 2,37 & 2,55 \\
Abril & 231 & $-0,43$ & 5,46 & 6,65 \\
Maio & 238 & 3,03 & 1,45 & 2,77 \\
Junho & 244 & 2,52 & 2,35 & 1,98 \\
Julho & 236 & $-3,28$ & 0,90 & 2,12 \\
Agosto & 231 & $-2,12$ & 5,45 & 6,74 \\
\hline
\end{tabular}

Fonte: Conjuntura Econômica, vários números, apud Mesquita (1992, p. 310 e 319).

Nota: * Índice dessazonalizado.

Apesar de o governo ter cedido em sua política de estabilização com o lançamento das Instruções n 206 e 207, os empresários industriais e comerciais não se viram ainda satisfeitos com o aumento real do crédito ao setor privado ocorrido em maio de 1961. Em reunião na FIESP em junho, por exemplo, argumentou-se que a concessão de maiores empréstimos à indústria não levaria à inflação, mas, sim, resultaria em "verdadeiro combate" a ela. Foi assinalado, também, que a restrição creditícia, ao impor limites à produção fabril, estaria trazendo ao País sérias implicações negativas, tais como o aumento do desemprego. A fim de expor os problemas do setor ao Presidente da República e às autoridades econômicas responsáveis, formou-se uma comissão de representantes dos industriais para ir até Brasília. O Presidente da Confederação Nacional da Indústria (CNI), José Villela Andrade Júnior, também participou dessa comissão. ${ }^{22}$ No mesmo dia, ao tomar conhecimento das críticas feitas pela FIESP à política econômica, o Presidente do Banco do Brasil lançou nota afirmando que as classes produtoras poderiam "ficar tranquilas", pois o governo não deixaria de suprir as "atividades legítimas" com os empréstimos a elas necessários. ${ }^{23}$

Ainda no final de junho de 1961, a diretoria da FIESP ratificou o posicionamento de que as Instruções n 206 e 207 se caracterizariam como ações insuficientes para conter a falta de numerário do mercado e que, portanto, outras medidas deveriam ser tomadas, tais como uma nova redução dos depósitos compulsórios e a supressão da necessidade de compra de Letras do Banco do Brasil. Decidiu-se, novamente, pela formação de um grupo de representantes empresariais com o intuito de con-

22 OESP (16.06.1961, p. 21)

23 Idem. Para posição semelhante dos empresários do comércio, ver OESP (29.06.1961, p. 22; e 05.07.1961, p. 18). 
versar com o Ministro da Fazenda e com o Presidente do Banco do Brasil sobre o problema do crédito. No dia 26 de junho, realizou-se o encontro. Uma exposição da Federação do Comércio do Estado de São Paulo sobre a escassez creditícia no País, assinada pela ACSP, também foi encaminhada às autoridades. O Ministro da Fazenda, Clemente Mariani, disse aos industriais que iria reunir-se naquele mesmo dia com a equipe da SUMOC, a fim de normalizar, o quanto antes, as atividades de crédito. ${ }^{24}$

Menos do que uma semana depois, no dia $1^{\circ}$ de julho de 1961, a SUMOC publicaria a Instrução $n^{\circ} 208$, que não apenas afrouxou a restrição do crédito ao setor privado (na medida em que regulamentou nova redução do compulsório), como também estabeleceu uma política mais flexível no que se referia às importações, pois, a partir de então, as máquinas e equipamentos importados foram liberados da obrigatoriedade de compra das Letras do Banco do Brasil.

As classes empresariais aplaudiram a decisão. Em reunião da FIESP, o diretor do Departamento de Economia Industrial da Federação, Sérgio Ugolini, declarou que a diminuição dos compulsórios iria "melhorar a situação do crédito solicitada pelas nossas entidades" e que a decisão de liberar as máquinas e os equipamentos da compra das Letras do Banco do Brasil englobaria aspectos "que há muito vinham sendo debatidos pelas nossas Casas". 25 O Presidente da ACSP, Camilo Ansarah, declarou que a Instrução n 208 teria complementado a instrução anterior e que a tendência seria a de significativa melhora no problema do crédito para as empresas. ${ }^{26} \mathrm{~A}$ diretoria da SRB também apoiou a medida. Diferentemente dos industriais e dos comerciantes, no entanto, os representantes da classe agrícola destacaram como principal ponto positivo dessa medida não a questão da ampliação do crédito, mas, sim, a da conclusão do processo de unificação das taxas cambiais, via extinção do câmbio de custo. ${ }^{27}$

Se, por um lado, as classes empresariais defenderam - e, até certo ponto, conseguiram - uma política mais liberal em termos do crédito bancário; por outro, elas manifestaram-se contrárias a qualquer tipo de política que garantisse reajustes salariais periódicos aos trabalhadores. As entidades empresariais interpretavam a expansão creditícia como uma política governamental "desinflacionaria”, na medida em que os empréstimos contribuiriam para uma maior capitalização das empresas e, consequentemente, para o aumento da oferta de bens na economia. Os reajustes salariais, diferentemente, na visão do empresariado, fomentariam uma elevação nos índices de preços. Isso ocorreria em razão da expansão da demanda resultante

24 OESP (27.06.1961, p. 27 e 29.06.1961, p. 22)

25 OESP (11.07.1961, p. 26).

26 OESP (05.07.1961, p. 18). Ver também Ata da 62 ${ }^{\circ}$ RDP da ACSP (04.07.61, p. 6-13).

27 OESP (04.07.1961, p. 24). 
de um aumento de poder de compra dos trabalhadores; demanda esta, segundo os empresários, que não teria condições de ser suprida a contento pelas empresas.

O debate sobre salários atingiu seu ponto máximo com a apresentação do projeto de salário móvel pelo deputado Fernando Ferrari (Movimento Trabalhista Renovador [MTR]-RS) ao Congresso Nacional, em abril de $1961 .{ }^{28}$ O Presidente da ACSP, por exemplo, afirmou que o projeto poderia gerar instabilidade social no País, na medida em que iria

(...) comprometer o sucesso da política de estabilização monetária do atual governo, (pois) além de ser de difícil aplicação, não satisfaria aos desejos dos operários e não contribuiria para um clima de tranquilidade social, necessária ao desenvolvimento econômico do Brasil. ${ }^{29}$

A Assessoria Jurídica da FIESP também elaborou um parecer sobre o assunto, enviando-o não apenas ao Presidente da República, mas também a vários parlamentares, líderes de partidos e ao Vice-Presidente do Senado. Nesse parecer, a Assessoria Jurídica classificou o projeto de "inconstitucional" e de "inconveniente". Além de criticar os supostos efeitos inflacionários contidos na concepção de salário móvel, os assessores da FIESP sustentaram que a manutenção dos dissídios coletivos, agregada à concessão de reajustes periódicos, constituiria um "absurdo". Por fim, o parecer afirmava que o órgão que determinava os porcentuais de reajustes (o Conselho Nacional de Economia) se transformaria em "verdadeiro barômetro do sistema e exerceria autêntica ditadura salarial". ${ }^{30}$

Para contentamento das classes empresariais, o projeto não chegou a ser aprovado durante o governo Quadros. O fato mais importante a salientar desse episódio, porém, é a maneira pela qual os empresários avaliaram com pesos diferentes os custos da política de estabilização. Em várias de suas manifestações públicas, as entidades patronais chegaram a apoiar a ideia de uma distribuição igualitária dos custos da estabilização entre os diferentes grupos sociais; todavia, em termos práticos, o empresariado buscou defender ou ampliar sua fatia da renda em detrimento

28 Esse projeto estabelecia reajustes salariais de seis em seis meses aos trabalhadores, desde que a inflação atingisse, no semestre anterior ao do reajuste, um patamar superior ao de $5 \%$. O índice utilizado para a medição do aumento dos preços seria o do Conselho Nacional de Economia (CNE). Além desses reajustes automáticos, manter-se-iam também os dissídios coletivos. Para maiores informações, ver a íntegra do projeto do deputado Fernando Ferrari em OESP (29.04.1961, p. 3). Vale assinalar que a concepção de que as medidas de expansão creditícia se configurariam como "desinflacionárias" foi exposta pelo chefe do Departamento Econômico da FIESP em reunião da diretoria desta entidade. Ver OESP (20.06.1961, p. 23).

29 OESP (06.05.1961, p. 16).

30 OESP (22.06.1961, p. 22). Para argumentos semelhantes, mas voltados para o trabalhador do campo, ver $A R\left(\mathrm{n}^{\mathrm{o}} 484,08.1961\right.$, p. 39 e 57$)$. 
dos demais segmentos da sociedade, entre os quais os trabalhadores. Esse tipo de postura dos empresários ficaria ainda mais evidente com a discussão do projeto da lei antitruste, que será apresentada na seção seguinte.

\section{O Projeto Antitruste}

Ao anunciar as primeiras medidas da reforma cambial, em março de 1961, o Presidente Jânio Quadros demonstrou consciência de que tais ações suscitariam, inevitavelmente, aumentos nos preços de alguns produtos. Segundo Jânio, esses acréscimos seriam, no entanto, muito reduzidos e logo absorvidos pela economia. ${ }^{31}$ Esse diagnóstico foi ratificado, posteriormente, por diversas declarações realizadas pelos responsáveis pela política monetária. Dizia-se que a "verdade cambial" funcionaria como um remédio para o País: no início, seria amargo; depois, garantiria vigor e sustentabilidade para o crescimento econômico. ${ }^{32}$

É razoável supor, por um lado, que muito do que fora declarado não passava de um recurso utilizado para acalmar o mercado, a fim de evitar um surto inflacionário; mas, por outro, deve-se lembrar que o governo não permaneceu apenas no plano da retórica no que se referia à contenção do aumento dos preços. Ao menos nos primeiros meses, a política monetária, por exemplo, foi bastante restritiva. Entre fevereiro e abril de 1961, os empréstimos reais ao setor privado apresentaram crescimento negativo $(-7,21 \%)$, como pode ser visto na Tabela 1. À primeira vista, portanto, parece mais consistente afirmar, tal como o faz Mesquita, que os policy makers teriam subestimado as consequências inflacionárias de sua política econômica, supondo que a economia brasileira apresentasse um cenário de concorrência perfeita (MESQUITA, 1992, p. 81).

Mesmo essa interpretação de Mesquita, no entanto, apresenta limitações. Uma das bases da concepção de política econômica de Jânio Quadros - anunciada ainda durante a sua campanha à presidência - era a de que a reforma cambial não resolveria sozinha as pressões inflacionárias. Segundo Quadros, para acabar com a inflação, seria preciso, além disso, substituir os mecanismos de controle de preços então existentes na economia por uma legislação mais ampla, capaz de fiscalizar as empresas não apenas no ato da venda dos produtos, mas, também, em todas as etapas

31 Jânio afirmou, por exemplo, que a desvalorização em 100\% do câmbio de custo geraria acréscimos de, no máximo, $2 \%$ nos preços dos bens de primeira necessidade, e de 3 a $4 \%$ nos preços dos bens produzidos a partir do trigo. OESP (14.03.1961, p. 6).

32 Para discursos de autoridades monetárias nesse sentido, ver OESP (14.03.1961, p. 6; 26.03.1961, p. 6; e 20.04.1961, p. 5-7). 
da produção. ${ }^{33} \mathrm{O}$ major Maurício Cibulares, Presidente da Comissão Federal de Abastecimentos e Preços (COFAP) do governo Quadros, expressou com clareza essas ideias em março de 1961:

O governo disporá de uma lei, que vem sendo denominada de antitruste, que lhe permitirá intervir com maior rigor no setor de preços, para controlar o lucro das empresas em todas as fases, desde a produção, e não apenas na fase da venda no varejo $(\ldots . .)^{34}$

Tendo em vista tal posicionamento, não se pode, portanto, atribuir ao governo Quadros uma visão ingênua, ou mesmo limitada, sobre as estruturas de mercado domésticas. As autoridades demonstraram consciência de que a economia brasileira estava longe de um cenário de concorrência perfeita e de que seria necessário, em razão disso, intervir de maneira mais incisiva sobre as empresas, coibindo a existência de quaisquer instrumentos que permitissem aos agentes econômicos controlar os preços dos produtos.

É dentro desse contexto que se deve compreender o envio ao Congresso Nacional, em abril de 1961, do anteprojeto da lei antitruste pelo governo Quadros. Na justificativa do anteprojeto, afirma-se que os órgãos responsáveis pelo controle de preços então existentes no Brasil, tais como a COFAP, estariam despreparados para a tarefa de penalização dos grandes "abusos econômicos". Entre os "abusos" listados como crimes pelo anteprojeto, destacam-se (i) o da retenção de estoques com fins especulativos; (ii) a formação de monopólios ou de oligopólios com o propósito de majorar preços; (iii) o parcelamento de empresas visando desrespeitar a legislação tributária; (iv) a promoção da cessão total ou parcial das atividades empresariais em proveito próprio ou de terceiros; (v) a burla de concorrências públicas mediante combinação de preços; (vii) o reajuste de "preços de vendas ou de mercadorias de consumo, sem que tenha ocorrido a efetiva majoração de qualquer de seus componentes", e (vii) a elevação abusiva dos "preços de mercadorias de consumo, para obter lucros maiores do que os normais". O anteprojeto previa também a criação de um órgão responsável pela fiscalização das empresas e pelo envio dos processos criminais ao Judiciário: a Comissão Administrativa de Defesa Econômica (CADEC). Essa Comissão seria subordinada ao Ministério da Justiça. Por fim, estipulava-se que os diretores, gerentes e proprietários de empresas acusadas de cometerem "abusos de

33 Ver o discurso pronunciado por Jânio Quadros no comício de Recife, em setembro de 1960, em OESP (04.09.1960, p. 6; 05.09.1960, p. 5-7). Para análise da plataforma do governo janista, ver ARNT (2004, p. 133), Cardoso (1978, p. 287-318), Victor (1965, p. 37-65). Sobre os mecanismos de controle de preços no Brasil no início da década de 1960, especialmente acerca da Comissão Federal de Abastecimento e Preços (COFAP) - órgão responsável pelo tabelamento dos preços dos bens de primeira necessidade -, ver Abreu (2001, p. 1466, v. II).

$34 \operatorname{OESP}$ (25.03.1961, p. 14). 
poder econômico" seriam criminalizados nos termos do Código do Processo Penal, o que envolveria, além de multas, a prisão dos responsáveis. ${ }^{35}$

Vê-se que a lei antitruste, caso fosse aprovada, não só ampliaria consideravelmente o rol de ações consideradas ilegais pelo Estado no que tange à política de formação de preços pelas empresas (estruturação de monopólios e oligopólios, aumento de preços para além da elevação dos custos, especulação com estoques, etc.), como, também, forneceria à CADEC instrumentos de penalização bem maiores do que os até então existentes. Em outras palavras: se essa lei fosse aplicada à risca pelo poder público, as empresas teriam uma margem de manobra bem menor para majorar os preços dos seus produtos.

Nesse sentido, não é de se estranhar o fato de que, desde o início, a tramitação do anteprojeto da lei antitruste pelas comissões do Parlamento tenha sido acompanhada de perto pelas entidades empresariais. ${ }^{36}$ A FIESP e a Federação das Associações Comerciais (FAC) não apenas enviavam representantes para a maioria das reuniões das Comissões de Justiça, de Economia e de Finanças do Congresso, onde o tema foi amplamente debatido, como, também, abordavam diretamente parlamentares constituintes dessas comissões, a fim de impedir que o anteprojeto fosse aprovado em suas linhas originais. ${ }^{37}$ Inúmeros foram os pareceres da FIESP, da FAC, da ACSP e da CNC entregues ao Presidente da República, ao Presidente da Câmara, ao Vice-Presidente do Senado, aos líderes partidários e aos deputados e senadores em geral. ${ }^{38}$

Entre os aspectos do anteprojeto da lei antitruste considerados "prejudiciais à economia brasileira” pelos empresários da indústria e do comércio, destaca-se, em primeiro lugar, a concepção de que ele desrespeitaria um dos pilares constituintes da economia nacional: o da livre iniciativa. Segundo as próprias palavras da Assessoria Jurídica da FIESP:

É preciso, antes de tudo, ter em vista que a ordem econômica em nosso País repousa na livre iniciativa, na liberdade de empreendimento, condicionada à valorização do trabalho e tendo por fim a instauração da justiça social (...). A lei de repressão aos abusos econômicos deve configurar-se em consonância com a filosofia de tutela da liberdade de concorrência, e não em termos de dirigismo econômico de feito totalitário (...). ${ }^{39}$

35 Ver o anteprojeto em OESP (06.04.1961, p. 2).

36 UH (26.05.61, lc, p. 4).

37 OESP (26.05.1961, p. 5).

38 OESP (26.04, p. 22; 03.05, p. 21, 03.05, p. 21; e 09.05.1961, p. 27) e UH (13.06.1961, lc, p. 4).

39 OESP (09.05.1961, p. 27). 
Já a FAC, em seu parecer, assinalou que o desrespeito à livre iniciativa, embutido no anteprojeto do governo, representaria "a negação da própria existência do regime econômico consagrado em nossa Magna Carta". ${ }^{40}$ A ACSP, por sua vez, seguiu o mesmo posicionamento, afirmando que o anteprojeto aniquilaria a liberdade econômica nacional e, por extensão, o próprio regime democrático. ${ }^{41}$

Em segundo lugar, as entidades patronais consideraram por demais abrangentes os crimes enquadrados no rol dos "abusos de poder econômico", especialmente aqueles que se referiam à proibição do aumento de preços nos casos em que não existissem acréscimos de custos, à criminalização dos monopólios e oligopólios, à obtenção de lucros vistos como excessivos e à cessação total ou parcial de empreendimentos em benefício próprio ou de terceiros. Com relação à impossibilidade de elevação dos preços, por exemplo, a FIESP previa consequências como a paralisação da concorrência e a estagnação tecnológica:

O aumento ou diminuição de preços resultam do livre jogo do mercado. Subordiná-los ao aumento de custo equivale não só a promover a estagnação técnica - porque ninguém terá maior interesse em diminuir seus custos -, como também a desestimular a entrada de novos concorrentes. ${ }^{42}$

No que diz respeito, por outro lado, ao problema da formação de monopólios e oligopólios, a posição dos industriais e dos comerciantes também foi coesa: segundo eles, em um País como o Brasil, possuidor de um mercado relativamente estreito, havia setores que não comportariam um número muito grande de empresas. Além disso, as entidades empresariais sustentaram que, em certos domínios econômicos, não haveria condições para o aparecimento de um número elevado de concorrentes. Em ambos os casos, portanto, de acordo com os empresários, monopólios e oligopólios poderiam ser estabelecidos sem que houvesse desrespeito à "livre iniciativa". ${ }^{43}$ A Assessoria Jurídica da FIESP chegou até a afirmar que, mesmo sem essas condições, "haver[ia] sempre a concorrência estrangeira" e que, portanto, certos tipos de trustes deveriam ser interpretados como benéficos para o fortalecimento da "economia nacional". 44

No que se refere à limitação dos lucros, as entidades patronais argumentaram que as empresas deveriam ter a expectativa de auferir ganhos razoáveis em seus respectivos empreendimentos, caso contrário, a "livre iniciativa" não encontraria incentivos para

40 OESP (26.04.1961, p. 22)

41 OESP (03.05.1961, p. 21); Ata da $48^{\circ}$ RDP da ACSP (28.03.61, p. 4a-4f).

42 OESP (09.05.1961, p. 27)

43 OESP (03.05.1961, p. 21).

44 OESP (09.05.1961, p. 27) 
realizar inversões. ${ }^{45}$ Sobre a criminalização do encerramento total ou parcial dos empreendimentos, a posição dos empresários também foi taxativamente contrária ao texto do anteprojeto, alegando, entre outros aspectos, desrespeito ao direito de liberdade do cidadão:

(...) não é possível, como quer o projeto, incriminar o agente em virtude dos resultados do ato, os quais poderiam não estar sob o controle ou na previsão do sujeito. Além do mais, a cessação de uma atividade econômica, sem intuito lesivo, constitui ato perfeitamente normal e lícito, não podendo o agente ser responsabilizado pelas consequências que disso advenham eventualmente, como o desemprego e a elevação de preços. Seria atentar contra a propriedade de uma pessoa, constrangê-la a continuar a exploração de uma empresa deficitária, até a sua completa ruína. ${ }^{46}$

Em terceiro lugar, os empresários censuraram a concentração de poderes que o anteprojeto concedia à CADEC, no que dizia respeito à fiscalização e execução de penalidades contra as empresas. Argumentou-se que essa excessiva centralização desrespeitava, entre outros pontos, a própria Constituição, pois negligenciava a existência do pacto federativo nacional. As entidades foram também muito críticas quanto às penalidades previstas pelo anteprojeto. Considerou-se abusiva a aplicação de penas "não econômicas" - no caso, o aprisionamento dos responsáveis - para crimes que se configurariam como "estritamente econômicos". 47 A CNC, em seu parecer, chegou a condicionar a cooperação da classe empresarial com o governo Quadros à supressão desses aspectos do anteprojeto da lei antitruste:

Confiantes no regime da livre concorrência, (as empresas) mal sabem que podem, a qualquer instante, ser chamadas às barras do tribunal, ou ter suas atividades invadidas, seus livros e arquivos apreendidos e vasculhados, com as piores repercussões no meio da clientela e acabando em ruinoso desfecho (...). O clima de cooperação desejado pelo governo do eminente Presidente Jânio Quadros, por parte de todos os setores da vida econômica nacional, está em nossos desejos e é alvo de nossos esforços. Como condição, entretanto, da vigência desse clima, urge que as atividades produtivas não se vejam sitiadas por um aparelhamento inquisitorial, susceptível de implantar a intranquilidade e a inse-

45 OESP (03.05.1961, p. 21).

46 Parecer da Assessoria Jurídica da FIESP sobre o anteprojeto da lei antitruste. OESP (09.05.1961, p. 27).

47 Ver, para esse posicionamento, o parecer da FAC sobre as penalidades instituídas pelo anteprojeto da lei antitruste. OESP (03.05.1961, p. 21). 
gurança, desencorajando a empresa progressista em seus legítimos e patrióticos movimentos". ${ }^{4}$

A tramitação do anteprojeto no Congresso foi bastante tumultuada. As críticas feitas pelas entidades empresariais foram apoiadas por muitos parlamentares, principalmente por membros da União Democrática Nacional (UDN) e do Partido Social Democrático (PSD). Dos debates, apareceram dois fortes substitutivos ao anteprojeto original: o de Ulysses Guimarães (PSD-SP, Comissão de Constituição e Justiça) e o de Jacob Franz (Partido Trabalhista Brasileiro [PTB]-PB, Comissão de Economia). Ulysses Guimarães modificou substancialmente a proposta do governo: diminuiu o poder do CADEC - agora denominado apenas Conselho Administrativo de Defesa Econômica (CADE) -; diferenciou os "pequenos" dos "grandes" abusos econômicos, e abrandou as penalidades referentes aos lucros excessivos e aos aumentos de preços sem base nos acréscimos dos custos. Jacob Franz, diferentemente, alterou apenas aspectos pontuais da proposta janista, mantendo suas linhas básicas, tais como a centralização decisória no CADE; a manutenção da lista de crimes antes considerados passíveis de serem tratados como de abuso do poder econômico, entre outros aspectos. ${ }^{49}$

O embate ganhou contornos mais sérios com as decisões da COFAP de desapropriar produtos ou reter lucros das empresas privadas consideradas responsáveis pela manutenção de estoques com finalidades especulativas. O Presidente da República assinou outros decretos com o mesmo fim antes mesmo do envio do anteprojeto da lei antitruste ao Congresso, versando contra refinarias de petróleo, empresas distribuidoras de fertilizantes inseticidas, bem como atacadistas e empresários agrícolas negociadores de trigo. ${ }^{50}$ Como reação, muitos parlamentares argumentavam que o CADE se transformaria em uma COFAP piorada, pois usufruiria de maiores poderes e seria capaz de desrespeitar ainda mais as liberdades dos agentes econômicos. ${ }^{51}$

As divisões existentes no Congresso entre os parlamentares favoráveis e contrários ao anteprojeto do governo foram reproduzidas na Comissão de Economia da Câmara, onde o substitutivo Jacob Franz (que era o que mais se assemelhava à proposta janista) estava sendo votado. Após escrutínio apertado, o substitutivo foi aprovado por aquela Comissão. O deputado Gileno de Carli (PSD-PE), porém, baseado em uma norma regimental da Casa, conseguiu invalidar a votação, causando revolta nos partidários de Jacob Franz. Em sinal de repúdio a esse ato, Franz renun-

48 OESP (03.05.1961, p. 21).

49 OESP (18.04.1961, p. 4, e 14.05.1961, p. 6)

50 Ver OESP (16.03.1961, p. 2).

51 Ver, por exemplo, as declarações do deputado do PSD, Oliveira Brito. OESP (06.04.1961, p. 2). 
ciou ao cargo de relator da matéria. ${ }^{52}$ Para piorar, após duas semanas, a Comissão de Constituição e Justiça considerou inconstitucional o artigo referente ao CADE contido no substitutivo. ${ }^{53}$ Todos esses percalços impediram que o anteprojeto do governo e os respectivos substitutivos fossem enviados ao Parlamento para serem discutidos e votados com rapidez - o que beneficiava as classes empresariais. Quando da renúncia de Jânio, em agosto de 1961, a lei antitruste não havia sido votada. Ela só seria aprovada um ano depois, porém, com um conteúdo completamente diferente do projeto original. Na versão final, todos os artigos considerados negativos pelo empresariado foram retirados. Por exemplo, a redação acerca dos crimes que seriam considerados "abusos de poder econômico" ficou bem mais branda e, ao mesmo tempo, vaga, permitindo amplo leque de interpretações. As penas imputadas aos diretores, gerentes e proprietários das empresas tornaram-se apenas de natureza econômica (multas de até mil vezes o salário mínimo) - não mais envolvendo prisão, por exemplo -, e o CADE foi criado apenas com poder restrito de fiscalização sobre as empresas. 54

É difícil avaliar com precisão qual teria sido o peso das pressões das entidades patronais sobre os parlamentares a fim de que estes aprovassem - como eles o fizeram - uma lei antitruste adequada aos interesses das empresas. Será que pareceres enviados pelas entidades patronais aos deputados e senadores tinham importância para a definição das atitudes desses políticos? Qualquer consideração mais precisa sobre o grau de influência das entidades empresariais exigiria um estudo detalhado sobre a ligação dos parlamentares que votaram de acordo com as ideias defendidas pelos empresários e tais entidades - algo que se encontra completamente fora do escopo desse artigo. Por outro lado, parece bastante razoável inferir, a partir de evidências esparsas e indiretas, que a atuação empresarial não pode ser negligenciada na análise do projeto de lei antitruste. Coincidência ou não, o fato é que os principais argumentos utilizados pelos industriais e comerciantes foram incorporados pelo Congresso. Essa constatação parece suficiente para colocar em xeque a explicação da trajetória dessa lei no governo Quadros baseada na lógica interna da esfera estatal.

\section{Conclusões}

Neste artigo, argumentou-se, por meio da utilização de fontes referentes às entidades patronais da indústria, do comércio e da agricultura paulistas, que as alterações de rumo apresentadas pela política econômica do governo Quadros não se

52 OESP (28.06.1961, p. 4) e UH (29.06.1961, lc, p. 4).

53 OESP (07.07.1961, p. 3).

54 Para o texto na íntegra da lei antitruste, ver OESP (13.11.1962, p. 5-7). 
deveram, exclusivamente, às ações, inabilidades ou limitações dos agentes estatais, mas também às pressões exercidas pelas entidades empresariais sobre os órgãos governamentais.

Naturalmente, as pressões realizadas pelas associações patronais no governo também não foram a única influência sobre a formulação da política econômica do período. É claro que, em última instância, são os agentes estatais - sejam os governantes, os burocratas ou os técnicos - que executam as mudanças nos parâmetros das políticas públicas. A questão é saber, no entanto, até que ponto estes agentes teriam sido constrangidos pelas classes empresariais a executá-las, ou se eles, por convicção própria, teriam sido os principais responsáveis por tais mudanças, como muitos estudiosos defenderam. O problema desta última interpretação é que o argumento apóia-se em frágil base empírica. Mário Mesquita (1992) e Sérgio Monteiro (1999), por exemplo, apesar de afirmarem que as alterações ocorridas na política econômica de Quadros estariam diretamente relacionadas às vontades dos agentes estatais (para o primeiro, a vontade dos técnicos; para o segundo, a dos governantes), apresentam pouca ou nenhuma evidência das supostas aspirações desses agentes. As conclusões dos autores são, assim, mais um resultado lógico-dedutivo do que propriamente empírico.

Com relação ao argumento de Lourdes Sola (1998), para além do problema da frágil base empírica, acrescenta-se outra limitação. A autora apresenta uma visão instrumentalista de Estado, sugerindo que se o Estado possuísse as ferramentas institucionais corretas para debelar a crise (tal como a existência de um Banco Central), os problemas econômicos seriam automaticamente superados. Levando-se em consideração, porém, a intensidade das pressões empresariais sobre o governo apresentadas neste artigo, é de questionar-se a validade do argumento da autora.

Mesmo que não tenha sido o único fator, há evidências de que os empresários tiveram importância na modificação das diretrizes da política econômica janista. Sobre a política monetária, por exemplo, viu-se o quanto a demanda por créditos dos empresários em relação ao governo foi acompanhada de ameaças veladas de aumentos dos preços. Seja por meio de telegramas e memorandos, seja via encontros com autoridades monetárias, os empresários deixaram claro que não estavam dispostos a arcar sozinhos com os custos da reforma cambial. Não parece ter sido coincidência o fato de as Instruções n $n^{\circ}$ 206, 207 e 208 terem sido publicadas dias depois da realização dos encontros entre empresários e representantes do governo.

Apesar de mais complexo, devido ao envolvimento de um número maior de atores políticos, pode-se inferir conclusão semelhante com relação ao projeto original da lei antitruste. Caso tivesse sido aprovado, ele enfraqueceria o poder de barganha 
dos empresários em relação ao Estado, na medida em que inúmeras ações empresariais, antes legítimas (como, por exemplo, o aumento dos preços dos bens para além dos acréscimos dos custos de produção), se tornariam ilegais. Não foi à toa que as classes empresariais mobilizaram-se em peso contra vários dos seus artigos. É óbvio que não é possível delimitar, com precisão, até que ponto a pressão dos empresários foi determinante para a rejeição do projeto de lei antitruste. Todavia, não se pode negligenciar o esforço feito pelas entidades patronais a fim de arregimentar parlamentares contrários a tal lei. Além disso, muitos desses políticos dependiam, em maior ou menor medida, de auxílios financeiros fornecidos pelas entidades patronais para a campanha das eleições legislativas de outubro de 1962. É de se ressaltar, nesse sentido, que a aprovação de um substitutivo da lei antitruste absolutamente identificado com os interesses empresariais tenha-se dado exatamente um mês antes dessas eleições.

Pode-se afirmar, portanto, que as classes empresariais apresentaram um papel determinante - apesar de não ter sido o único - nas mudanças realizadas na política econômica ao longo do governo Quadros. Mais do que apenas a vontade dos agentes estatais, ou a inadequação de ferramentas de política econômica, os empresários também foram responsáveis pela falência da tentativa do governo de pôr em prática uma política de estabilização na economia. Esse insucesso teria significativas consequências para a evolução histórica brasileira subsequente. As posteriores tentativas de estabilização econômica realizadas durante o governo Goulart, tais como as do Gabinete Tancredo Neves, a do Plano Trienal e a do Ministro Carvalho Pinto, já nasceriam sob a égide da desconfiança por parte dos agentes econômicos. Se Jânio Quadros, com toda a legitimidade obtida a partir de uma inédita votação presidencial e ainda com o apoio do governo norte-americano, não conseguiu seguir à risca as diretrizes estipuladas pela sua equipe econômica com o intuito de estabilizar a economia, por que Goulart conseguiria? Essa desconfiança apareceu com certa frequência nas reuniões das entidades empresariais durante o interregno janguista e, ao que parece, contribuiu para as sérias dificuldades que se apresentaram para a aplicação das políticas de estabilização tentadas por esse governo. 


\section{Fontes}

\section{Jornais e Periódicos}

A Rural (AR)

Desenvolvimento e Conjuntura (DC)

O Estado de São Paulo (OESP)

Última Hora $(U H)$

\section{Arquivos de Entidades Patronais}

Biblioteca Roberto Simonsen - Instituto de Filosofia e Ciências Humanas da Universidade Estadual de Campinas (IFCH - Unicamp)

Biblioteca da Associação Comercial do Estado de São Paulo (ACSP)

Biblioteca da Sociedade Rural Brasileira (SRB)

\section{Referências}

ABREU, A. A. et alli. (Coord.). Dicionário histórico-biográfico brasileiro. Rio de Janeiro: Fundação Getúlio Vargas, 2001.

ABREU, M. P. Inflação, estagnação e ruptura: 1961-1964. In: . (Org.). A ordem do progresso. Cem anos de política econômica republicana (1889-1989). Rio de Janeiro: Campus, 1990. p. 197-211.

ARNT, R. Jânio Quadros. O prometeu da vila Maria. Rio de Janeiro: Ediouro, 2004.

BAER, W. A economia brasileira. 2. ed. São Paulo: Nobel, 2002.

BANDEIRA, M. A renúncia de Jânio Quadros e a crise pré-64. São Paulo: Brasiliense, 1970.

CARDOSO, M. L. A ideologia do desenvolvimento: JK-JO. Rio de Janeiro: Paz e Terra, 1978.

LEACOCK, R. Requiem for revolution. The United States and Brazil, 1961-1969. Kent / London: The Kent State University Press, 1990.

LEOPOLDI, M. A. P. Política de interesses na industrialização brasileira. As associações industriais, a política econômica e o Estado. São Paulo: Paz e Terra, 2000 .

MESQUITA, M. M. C. 1961-1964: a política econômica sob Quadros e Goulart. Dissertação (Mestrado) - PUC/RJ, Rio de Janeiro, 1992. 
MONTEIRO, S. M. M. Política econômica e credibilidade: uma análise dos governos Jânio Quadros e João Goulart. Tese (Doutorado) - UFRS, Porto Alegre, 1999.

SCHMITTER, P. C. Interest conflict and political change in Brazil. Standford: Standford University Press, 1971.

SKIDMORE, T. Brasil: de Getúlio a Castelo (1930-1964). 12. ed. São Paulo: Paz e Terra, 2000.

SOLA, L. Idéias econômicas, decisões políticas. São Paulo: Edusp, 1998.

VICTOR, M. Cinco anos que abalaram o Brasil. De Jânio Quadros ao Marechal Castelo Branco. Rio de Janeiro: Civilização Brasileira, 1965. 